\title{
ADAMPAK PENGAWASAN MELEKAT DAN MOTIVASI TERHADAP DISIPLIN KARYAWAN PT. KERETA API INDONESIA DIVISI REGIONAL TANJUNG KARANG
}

\author{
Zuriana1 $^{1}$, Aditya Kurniawan²
}

Fakultas Bisnis dan Ekonomi, Informatics \& Business Institute Darmajaya

Email : Zuriana@darmajaya.ac.id¹, adityakurniawan271@gmail.com²

\section{ABSTRACT}

This study aims to analyze the effect of adhering supervision and work motivation on the work discipline of the employees in operation division of PT. Kereta Api Indonesia (Persero) Wilayah B Regional Division IV Tanjung Karang. This type of research is quantitative research. The population in this study was employees in operation division of the PT. Kereta Api Indonesia (Persero) Region B Tanjung Karang Regional Division IV which numbered 95 employees and all populations were used as samples.

Adhering supervision (waskat) and work motivation have a positive effect on employee work discipline both partially and simultaneously. The coefficient of determination $R^{2}$ (R Squares) of 0.186 shows that Work Discipline (Y) is influenced by Adhering Supervision (X1) and Work Motivation (X2) of $18.6 \%$.

Keywords: Adhering supervision, work motivation, and work discipline

\section{PENDAHULUAN}

\subsection{Latar Belakang}

PT. Kereta Api Indonesia (Persero) yang berada di Provinsi Lampung dan sebagian Sumatera Selatan berada pada Divisi Regional IV Tanjung Karang. Kereta api yang beroperasi pada regional ini adalah kereta api barang seperti kereta api batu bara rangkaian panjang, kereta api pulp/kayu, kereta api minyak bumi, layanan kereta api penumpang Limex Sriwijaya, Ekspress Rajabasa dan Kereta Api Diesel Way Umpu atau Seminung.

\section{Tabel 1.}

Penilaian Disiplin Kerja Karyawan Bagian Operasi Wilayah B Divisi Regional IV Tanjung Karang Tahun 2017

\begin{tabular}{clcccc}
\hline No & \multicolumn{1}{c}{ Tugas Pokok dan Fungsi } & Bobot & Target & Realisasi & Skor \\
\hline 1 & $\begin{array}{l}\text { Melaksanakan buka dan tutup stasiun sesuai } \\
\text { dengan peraturan dinas }\end{array}$ & $10 \%$ & 100 & 80 & 8,00 \\
2 & $\begin{array}{l}\text { Melayani Kereta Api datang, berangkat dan } \\
\text { langsung sesuai peraturan dinas }\end{array}$ & $35 \%$ & 100 & 80 & 28,00 \\
3 & $\begin{array}{l}\text { Melayani Permintaan langsir sesuai peraturan } \\
\text { dinas }\end{array}$ & $20 \%$ & 100 & 75 & 15,00 \\
4 & $\begin{array}{l}\text { Serah terima dinasan sesuai dengan } \\
\text { peraturan dinas }\end{array}$ & $10 \%$ & 80 & 70 & 8,75 \\
5 & $\begin{array}{l}\text { Melayani Perjalanan Kereta Api dalam kondisi } \\
\text { tidak normal sesuai prosedur }\end{array}$ & $15 \%$ & 100 & 80 & 12,00 \\
6 & Administrasi Perka tertulis dengan tertib & $10 \%$ & 80 & 70 & 8,75 \\
\hline$\quad$ Total Skor & & & & 80,50 \\
\hline
\end{tabular}

Sumber: PT. Kereta Api Indonesia (Persero), 2017 
Untuk menunjang kegiatan perusahaan terdapat 16 unit organisasi yang memiliki tugas pokok dan fungsinya masing-masing di Divisi Regional IV Tanjung Karang. Khusus unit operasi adalah karyawan yang betugas untuk mengoperasikan (operator) sarana dan prasarana kereta api. Unit operasi di Divisi Regional IV Tanjungkarang dibagi menjadi beberapa bagian yaitu UPT Stasiun Wilayah A, $B, C, D$ dan UPT Crew KA. Pada penelitian ini penulis hanya akan melakukan penelitian pada Operasi Prasarana Wilayah B saja yang memiliki batas wilayah dari Stasiun Sulusuban sampai dengan Stasiun Negeri Agung.

Pada Tabel 1 menunjukkan bahwa berdasarkan penilaian pada tahun 2017, tingkat disiplin kerja karyawan bagian operasi wilayah B Divisi Regional IV dengan total skor 80,50 masih belum mecapai target (total skor 100). Dengan demikian dapat disimpulkan bahwa disiplin kerja karyawan masih belum maksimal.

Pelaksanaan pengawasan operasi di wilayah B Divisi Regional IV Tanjung Karang menjadi tanggung jawab senior manajer operasi, quality controller IV B dan KUPT Stasiun. Fungsi dan tanggung jawab Senior Manajer Operasi, quality controller dibantu oleh KUPT stasiun adalah melaksanakan pemantauan, pengawasan, pemeriksaan dan pembinaan mutu pekerjaan teknis operasi dan pelayanan, kebersihan, keamanan dan ketertiban di stasiun operasional di wilayah B.

Kegiatan pengawasan yang dilakukan di wilayah B Divisi Regional IV Tanjung Karang selama tahun 2017 adalah pembinaan 10 kali, inspeksi stasiun 26 kali dan cek lintas 29 kali. Tetapi masih terjadi pada bulan-bulan tertentu tidak ada pembinaan, inspeksi dan cek lintas oleh pimpinan seperti pengawasan melekat atau dalam hal ini senior manajer operasi dan quality controller langsung mengawasi kerja karyawan atau melakukan pembinaan, inspeksi bersifat tentatif dan hanya beberapa kali dalam sebulan. Hal ini menyebabkan karyawan kurang disiplin karena merasa kurang diperhatikan atau diawasi.

Selain pengawasan melekat, motivasi kerja dapat meningkatkan disiplin kerja karyawan. Sutrisno $(2016,109)$ mengatakan bahwa motivasi kerja adalah suatu faktor yang mendorong seseorang untuk melakukan suatu aktivitas tertentu, oleh karena itu motivasi sering kali diartikan pula sebagai faktor pendorong perilaku seseorang. Maka dapat disimpulkan, perusahaan bukan saja mengharapkan pegawai mampu, cakap dan terampil tapi yang terpenting mereka dapat bekerja giat dan berkeinginan untuk mencapai hasil kerja yang maksimal.

Untuk meningkatkan motivasi kerja
karyawan penghargaan kepada karyawan, hal ini diatur dalam perjanjian kerja bersama antara PT Kereta Api Indonesia dan Serikat Pekerja Kereta Api (SPKA) Pasal 49 ayat 1. Namun pemberian penghargaan atas prestasi dan jasa karyawan bagian operasi wilayah $\mathrm{B}$ masih sangat jarang. Sehingga karyawan kurang termotivasi untuk bekerja sesuai dengan standar operasional atau aturan yang berlaku.

\subsection{Perumusan Masalah}

1. Bagaimana pengaruh pengawasan melekat terhadap disiplin kerja karyawan PT. Kereta Api Indonesia Divisi Regional IV Tanjung Karang?

2. Bagaimana pengaruh motivasi kerja terhadap disiplin kerja karyawan PT. Kereta Api Indonesia Divisi Regional IV Tanjungkarang?

3. Bagaimana pengaruh pengawasan melekat dan motivasi kerja terhadap disiplin kerja karyawan PT. Kereta Api Indonesia Divisi Regional IV Tanjung Karang?

\subsection{Tujuan Penelitian}

1. Mengukur besarnya pengaruh pengawasan melekat terhadap disiplin kerja karyawan PT. Kereta Api Indonesia Divisi Regional Tanjung Karang.

2. Mengukur besarnya pengaruh motivasi kerja terhadap disiplin kerja karyawan PT Kereta Api Indonesia Divisi Regional Tanjung Karang.

3. Mengukur besarnya pengaruh pengawasan melekat dan motivasi kerja terhadap disiplin kerja karyawan PT. Kereta Api Indonesia Divisi Regional IV Tanjung Karang. 


\section{TINJAUAN PUSTAKA}

\subsection{Pengawasan Melekat (waskat)}

Menurut Hasibuan (2014, 196) pengawasan melekat (waskat) adalah tindakan nyata dan efektif dalam mewujudkan kedisiplinan karyawan perusahaan. Dengan waskat berarti atasan harus aktif dan langsung mengawasi perilaku, moral, sikap, gairah kerja dan prestasi kerja bawahannya. Hal ini berarti atasan harus selalu ada atau hadir di tempat kerja agar dapat mengawasi dan memberikan petunjuk, jika ada bawahannya yang mengalami kesulitan dalam menyelesaikan pekerjaannya. Waskat efektif dalam merangsang kedisiplinan dan moral kerja karyawan. Karyawan merasa mendapat perhatian, bimbingan, petunjuk, pengarahan dan pengawasan dari atasannya.

Situmorang dan Juhir (dalam Utari, 2015) berpendapat bahwa pengawasan melekat sebenarnya merupakan salah satu fungsi manajemen yang terus dilakukan oleh setiap atasan sebagai pimpinan di samping perencanaan dan pelaksanaan karena itu pengawasan melekat sebenarnya bukan hal yang rumit, melainkan merupakan disiplin diri yang harus ditumbuhkan para setiap atasan untuk melakukannya.

Berdasarkan penjelasan dari beberapa pendapat para ahli tersebut, dapat disimpulkan bahwa pengawasan melekat adalah suatu kegiatan pemantauan, pemeriksaan dan evaluasi yang dilakukan oleh seorang atasan kepada bawahannya untuk mengusahakan, menetapkan, mengetahui dan menilai hasil dari pelaksanaan pekerjaan pegawai dengan maksud untuk mencegah atau meminimalisir terjadinya kesalahan dan penyimpangan serta dapat mengatasinya agar rencana yang telah dibuat dapat berjalan dengan baik sesuai target yang telah ditetapkan

Pengawasan melekat dalam penelitian ini akan diukur dengan beberapa indikator yang dikemukakan oleh Nurrahman (2014) yaitu a) Sosialisasi pengawasan melekat. b) Pelaksanaan pengawasan melekat. c) Pemeriksaan pengawasan melekat. d) Evaluasi dan tindak lanjut pengawasan melekat

\subsection{Motivasi Kerja}

Hasibuan $(2014,141)$ motivasi berasal dari kata latin movere yang berarti dorongan atau menggerakkan. Motivasi (motivation) dalam manajemen hanya ditujukan pada sumber daya manusia umumnya dan bawahan khususnya. Motivasi mempersoalkan bagaimana caranya mengarahkan daya dan potensi bawahan, agar mau bekerja sama secara produktif berhasil mencapai dan mewujudkan tujuan yang telah ditentukan.

Sutrisno (2016, 109) mengatakan bahwa motivasi adalah suatu faktor yang mendorong seseorang untuk melakukan suatu aktivitas tertentu, oleh karena itu motivasi sering kali diartikan pula sebagai faktor pendorong perilaku seseorang. Maka dapat disimpulkan bahwa perusahaan bukan saja mengharapkan pegawai mampu, cakap dan terampil tapi yang terpenting mereka dapat bekerja giat dan berkeinginan untuk mencapai hasil kerja yang maksimal. Kemampuan dan kecakapan pegawai sangat berguna bagi perusahaan jika mereka mau bekerja dengan giat. indikator-indikator motivasi kerja menurut Syahyuti (dalam Martanto, 2016), yaitu: a) Dorongan mencapai tujuan; b) Semangat kerja; c) Inisiatif dan kreatifitas; d) Rasa tanggung jawab

\subsection{Disiplin Kerja}

Singodimedjo dalam Sutrisno (2016, 86), mengatakan disiplin adalah sikap kesediaan dan kerelaan seseorang untuk mematuhi dan menaati norma-norma peraturan yang berlaku di sekitarnya. Disiplin karyawan yang baik akan mempercepat tujuan perusahaan, sedangkan disiplin yang merosot akan menjadi penghalang dan memperlambat pencapaian tujuan perusahaan. Disiplin menunjukkan sesuatu kondisi atau sikap hormat yang ada pada diri karyawan terhadap peraturan dan ketetapan perusahaan.

Menurut Soejono (dalam Mardiono, 2014) indikator dari disiplin kerja yaitu : a) Ketepatan waktu para karyawan datang ke kantor tepat waktu; tertib dan teratur, menyelesaikan pekerjaan teapt waktu dengan begitu dapat dikatakan disiplin kerja baik. b) 
Menggunakan peralatan kantor dengan baik; sikap hati-hati dalam menggunakan peralatan kantor, dapat menunjukkan bahwa seseorang memiliki disiplin kerja yang baik, sehinga peralatan kantor dapat terhindar dari kerusakan. c) Tanggung jawab yang tinggi; karyawan dapat menyelesaikan tugas yang dibebankan kepadanya sesuai dengan prosedur dan bertanggungjawab atas hasil kerja, dapat pula dikatakan memiliki disiplin kerja yang baik. d) Ketaatan terhadap aturan kantor; karyawan memakai seragam kantor, menggunakan kartu tanda pengenal, membuat ijin bila tidak masuk kantor, juga merupakan cerminan dari disiplin yang tinggi.

\subsection{Hipotesis}

1. Terdapat pengaruh pengawasan melekat terhadap disiplin kerja karyawan PT. Kereta Api Indonesia Divisi Regional IV Tanjung Karang.

2. Terdapat pengaruh motivasi kerja terhadap disiplin kerja karyawan PT. Kereta Api Indonesia Divisi Regional IV Tanjung Karang.

3. Terdapat pengaruh pengawasan melekat dan motivasi kerja terhadap disiplin kerja karyawan PT. Kereta Api Indonesia Divisi Regional IV Tanjung Karang.

\section{METODOLOGI PENELITIAN}

\subsection{Jenis Penelitian}

Jenis penelitian ini adalah kuantitatif yang berlandaskan pada filsafat positivisme, digunakan untuk meneliti pada populasi atau sampel tertentu, pengumpulan data menggunakan instrumen penelitian, analisis data bersifat kuantitatif/ statistik, dengan tujuan untuk menggambarkan dan menguji hipotesis yang telah ditetapkan. Sugiyono $(2017,32)$ menyatakan peneliti kuantitatif dalam melihat hubungan variabel terhadap objek yang diteliti lebih bersifat sebab akibat atau kausal, sehingga dalam penelitiannya ada variabel independen dan dependen.

Variabel Bebas (variabel independen) merupakan variabel yang mempengaruhi atau menjadi sebab perubahannya atau timbulnya variabel dependen. Dalam penelitian ini yang menjadi variabel independen adalah: pengawasan melekat, motivasi kerja. Variabel Terikat (variabel dependen) merupakan variabel yang dipengaruhi atau yang menjadi akibat karena adanya variabel bebas. Dalam penelitian ini yang menjadi variabel dependen ialah disiplin kerja.

\subsection{Populasi dan Sampel}

Pada penelitian ini, populasi penelitian adalah Karyawan Bagian Operasi PT Kereta Api Indonesia (Persero) Wilayah B Divisi Regional IV Tanjung Karang berjumlah 95 orang. Teknik sampling yang digunakan dalam penelitian ini adalah sampel total atau sensus. Menurut Sugiyono $(2017 ; 145)$ sampel total adalah teknik penentuan sampel bila semua anggota populasi digunakan sebagai sampel. Menurut Arikunto $(2010,131)$ jika subjek penelitian kurang dari 100 orang sebaiknya diambil semuanya, jika subjeknya besar atau lebih dari 100 orang dapat diambil $10-15 \%$ atau $20-25 \%$ atau lebih. Maka pada penelitian ini sampel sama dengan populasi yaitu 95 orang.

\subsection{Sumber Data}

Data primer adalah jawaban atas pernyataan yang dijawab oleh responden dengan membagikan kuesioner kepada karyawan bagian operasi PT Kereta Api Indonesia (Persero) Wilayah B Divisi Regional IV Tanjung Karang. Data Sekunder merupakan data yang diperoleh tidak langsung yaitu data tersebut diperoleh dari dokumen perusahaan dan buku. Dalam penelitian ini pengumpulan data melalui pihak organisasi yang bersangkutan yang sebelumnya sudah tersusun dan sudah dicatat seperti data jumlah karyawan. Metode pengumpulan data yang dilakukan dalam penelitian ini adalah dengan wawancara dan kuesioner, penelitian pustaka dan penelitian lapangan.

\subsection{Uji Persyaratan Instrumen Validitas dan Reliabilitas}

Suatu kuesioner dinyatakan valid jika pernyataan pada kuesioner mampu untuk mengungkapkan sesuatu yang akan diukur oleh kuesioner tersebut. Pengujian validitas tiap item pernyataan dilakukan dengan menghitung korelasi product moment antara skor item 
dengan skor total. Uji Reliabilitas bertujuan untuk mengetahui sejauh mana mengukur data memberikan hasil relatif konsisten bila dilakukan pengukuran ulang pada subyek yang sama, fungsi dari uji reliabilitas adalah mengetahui sejauh mana keandaan alat ukur atau kuesioner (angket) tersebut. Dalam SPSS uji yang sering dengan menggunakan metode Cronbach's Alpha .

\subsection{Metode Analisis Data}

Analisis regresi linier berganda digunakan untuk mengetahui seberapa besar pengaruh variabel bebas yaitu: pengawasan melekat dan motivasi kerja terhadap disiplin kerja karyawan PT. Kereta Api Indonesia Divisi Regional IV Tanjung Karang. Bentuk persamaan regresi linier berganda yang digunakan dalam penelitian ini adalah $Y=a+$ $b_{1} X_{1}+b_{2} X_{2}+e$

\subsection{Pengujian Hipotesis}

Uji $t$ digunakan untuk menguji signifikasi pengaruh parsial pengawasan melekat dan motivasi kerja terhadap disiplin kerja (Y) karyawan bagian operasi di PT Kereta Api Indonesia (Persero) Wilayah B Divisi
Regional IV Tanjung Karang. Jika nilai t hitung $>$ nilai $t$ tabel maka dapat dikatakan bahwa terdapat pengaruh yang signifikan antara variabel bebas terhadap variabel terikat secara parsial.

Uji $F$ digunakan untuk mengetahui apakah terdapat pengaruh secara simultan antara variabel bebas terhadap variabel terikat. Uji statistik mengikuti distribusi $F$ dengan derajat bebas $\mathrm{db} 1=\mathrm{k}$ dan $\mathrm{db} 2=\mathrm{n}-\mathrm{k}-1$, dengan $k$ adalah banyaknya parameter. Jika nilai $F$ hitung > nilai $F$ tabel maka dapat dikatakan bahwa terdapat pengaruh yang signifikan antara variabel bebas terhadap variabel terikat secara simultan.

\section{HASIL PENELITIAN PEMBAHASAN \\ 4.1 Hasil Uji Persyaratan Instrumen \\ a. Uji Validitas}

Hasil yang didapatkan yaitu keseluruhan nilai signifikasi lebih kecil dari alpha $(0,05)$, dan nilai rhitung lebih besar dari rtabel $(0,201)$, dimana nilai rhitung paling tinggi yaitu 0,743 dan paling rendah 0,225 . Dengan demikian seluruh item pernyataan pengawasan melekat dinyatakan valid

Tabel 2.

Uji Validitas Pengawasan Melekat

\begin{tabular}{cccccccc}
\hline $\begin{array}{c}\text { Item } \\
\text { Pernyataan }\end{array}$ & Sig & Alpha & r hitung & $r$ tabel & \multicolumn{2}{c}{ Kriteria Uji } & Simpulan \\
\hline Pernyataan 1 & 0,014 & 0,05 & 0,225 & 0,201 & Sig $<$ Alpha & $r$ hitung $>r$ tabel & Valid \\
Pernyataan 2 & 0,000 & 0,05 & 0,727 & 0,201 & Sig $<$ Alpha & $r$ hitung $>r$ tabel & Valid \\
Pernyataan 3 & 0,000 & 0,05 & 0,710 & 0,201 & Sig $<$ Alpha & $r$ hitung $>r$ tabel & Valid \\
Pernyataan 4 & 0,000 & 0,05 & 0,455 & 0,201 & Sig $<$ Alpha & $r$ hitung $>r$ tabel & Valid \\
Pernyataan 5 & 0,001 & 0,05 & 0,595 & 0,201 & Sig $<$ Alpha & $r$ hitung $>r$ tabel & Valid \\
Pernyataan 6 & 0,000 & 0,05 & 0,731 & 0,201 & Sig $<$ Alpha & $r$ hitung $>r$ tabel & Valid \\
Pernyataan 7 & 0,000 & 0,05 & 0,743 & 0,201 & Sig $<$ Alpha & $r$ hitung $>r$ tabel & Valid \\
Pernyataan 8 & 0,000 & 0,05 & 0,553 & 0,201 & Sig $<$ Alpha & $r$ hitung $>r$ tabel & Valid \\
\hline
\end{tabular}

Sumber : Hasil data diolah tahun 2018

Keseluruhan nilai signifikasi lebih kecil dari alpha $(0,05)$, dan nilai rhitung lebih besar dari rtabel $(0,201)$, dimana nilai rhitung paling tinggi yaitu 0,743 dan paling rendah 0,226 . Dengan demikian seluruh item pernyataan motivasi kerja dinyatakan valid. 
Hasil Uji Validitas Motivasi Kerja

\begin{tabular}{cccccccc}
\hline $\begin{array}{c}\text { Item } \\
\text { Pernyataan }\end{array}$ & Sig & Alpha & $r$ hitung & $r$ tabel & \multicolumn{2}{c}{ Kriteria Uji } & Simpulan \\
\hline Pernyataan 1 & 0.000 & 0.05 & 0,743 & 0.201 & Sig $<$ Alpha & $r$ hitung $>r$ tabel & Valid \\
Pernyataan 2 & 0.000 & 0.05 & 0,556 & 0.201 & Sig $<$ Alpha & $r$ hitung $>r$ tabel & Valid \\
Pernyataan 3 & 0.000 & 0.05 & 0,687 & 0.201 & Sig $<$ Alpha & $r$ hitung $>r$ tabel & Valid \\
Pernyataan 4 & 0.014 & 0.05 & 0,226 & 0.201 & Sig $<$ Alpha & $r$ hitung $>r$ tabel & Valid \\
Pernyataan 5 & 0.003 & 0.05 & 0,281 & 0.201 & Sig $<$ Alpha & $r$ hitung $>r$ tabel & Valid \\
Pernyataan 6 & 0.000 & 0.05 & 0,397 & 0.201 & Sig $<$ Alpha & $r$ hitung $>r$ tabel & Valid \\
Pernyataan 7 & 0.000 & 0.05 & 0,602 & 0.201 & Sig $<$ Alpha & $r$ hitung $>r$ tabel & Valid \\
Pernyataan 8 & 0.001 & 0.05 & 0,604 & 0.201 & Sig $<$ Alpha & $r$ hitung $>r$ tabel & Valid \\
\hline
\end{tabular}

Sumber : Hasil data diolah, 2018

Tabel 4.

Hasil Uji Validitas Disiplin Kerja

\begin{tabular}{cccccccc}
\hline $\begin{array}{c}\text { Item } \\
\text { Pernyataan }\end{array}$ & Sig & Alpha & r hitung & $r$ tabel & \multicolumn{2}{c}{ Kriteria Uji } & Simpulan \\
\hline Pernyataan 1 & 0.000 & 0.05 & 0.576 & 0.201 & Sig $<$ Alpha & $r$ hitung $>r$ tabel & Valid \\
Pernyataan 2 & 0.000 & 0.05 & 0.547 & 0.201 & Sig $<$ Alpha & $r$ hitung $>r$ tabel & Valid \\
Pernyataan 3 & 0.000 & 0.05 & 0.525 & 0.201 & Sig $<$ Alpha & $r$ hitung $>r$ tabel & Valid \\
Pernyataan 4 & 0.000 & 0.05 & 0.507 & 0.201 & Sig $<$ Alpha & $r$ hitung $>r$ tabel & Valid \\
Pernyataan 5 & 0.000 & 0.05 & 0.531 & 0.201 & Sig $<$ Alpha & $r$ hitung $>r$ tabel & Valid \\
Pernyataan 6 & 0.000 & 0.05 & 0.490 & 0.201 & Sig $<$ Alpha & $r$ hitung $>r$ tabel & Valid \\
pernyataan 7 & 0.000 & 0.05 & 0.382 & 0.201 & Sig $<$ Alpha & $r$ hitung $>r$ tabel & Valid \\
Pernyataan 8 & 0.000 & 0.05 & 0.450 & 0.201 & Sig $<$ Alpha & $r$ hitung $>r$ tabel & Valid \\
\hline
\end{tabular}

Sumber : Hasil data diolah, 2018

Keseluruhan nilai signifikasi lebih kecil dari alpha $(0,05)$, dan nilai rhitung lebih besar dari rtabel $(0,201)$, dimana nilai rhitung paling tinggi yaitu 0,576 dan paling rendah 0,382 . Dengan demikian seluruh item pernyataan disiplin kerja dinyatakan valid.

\section{b. Uji Reliabilitas}

Uji reliabilitas dilakukan untuk mengetahui konsistensi alat ukur dalam penggunaannya.

Tabel 5.

Hasil Uji Reliabilitas

\begin{tabular}{lcc}
\hline \multicolumn{1}{c}{ Variabel } & Nilai Cronbach's Alpha & N of Items \\
\hline Pengawasan Melekat (X1) & 0,747 & 8 \\
Motivasi Kerja (X2) & 0,624 & 8 \\
Disiplin Kerja (Y) & 0,574 & 8 \\
\hline
\end{tabular}

Sumber : Hasil data diolah tahun 2018

Dapat disimpulkan bahwa seluruh variabel telah memenuhi syarat reliabilitas instrument karena memiliki nilai sedang / cukup tinggi.

\subsection{Hasil Analisis Data}

Uji regresi linier berganda dilakukan untuk mengetahui arah hubungan antara variabel independen dengan variabel dependen apakah masing-masing variabel independen berhubungan positif atau negatif dan untuk 
memprediksi nilai dari variabel dependen apabila nilai variabel independen mengalami kenaikan atau penurunan.

Tabel 6.

Hasil Uji Regresi Linier Berganda

\begin{tabular}{cc}
\hline Nilai Korelasi $(\mathrm{R})$ & R Square $\left(\mathrm{R}^{2}\right)$ \\
\hline 0,431 & 0,186 \\
\hline
\end{tabular}

Sumber: Hasil data diolah tahun 2018

Pada tabel di atas diperoleh nilai koefisien determinasinya $\mathrm{R}^{2} \quad(R$ Square) sebesar 0,186 menunjukan bahwa disiplin kerja $(\mathrm{Y})$ dipengaruhi pengawasan melekat $\left(\mathrm{X}_{1}\right)$ dan motivasi kerja $\left(X_{2}\right)$ sebesar $18,6 \%$ sedangkan $81,4 \%$ dipengaruhi oleh faktor/variabel lain. Hubungan pengawasan melekat dan motivasi kerja terhadap disiplin kerja adalah sebesar 0,431 , hasil ini menunjukan hubungan yang cukup/sedang antara variabel pengawasan melekat $\left(X_{1}\right)$ dan motivasi kerja $\left(X_{2}\right)$ terhadap disiplin kerja $(Y)$. Persamaan regresinya $Y=$ $16,138+0,188 X_{1}+0,312 X_{2}$

\subsection{Hasil Pengujian Hipotesis}

Uji t atau uji parsial yaitu suatu uji untuk mengetahui pengaruh dari masingmasing variabel bebas terhadap variabel terikat secara parsial. Pengaruh pengawasan melekat terhadap disiplin kerja bahwa thitung sebesar 2,789 sedangkan tabel dengan dk (95-2) adalah 1,985 . Jadi thitung $(2,789)>$ tabel $(1,985)$. Kesimpulannya pengawasan melekat berpengaruh terhadap disiplin kerja karyawan bagian operasi PT Kereta Api Indonesia (Persero) Wilayah B Divisi Regional IV Tanjung Karang.

Pengaruh motivasi kerja terhadap disiplin kerja bahwa thitung sebesar 3,555 sedangkan tabel dengan dk (95-2) adalah 1,985. Jadi thitung $(3,555)>$ tabel $(1,985)$. Kesimpulannya motivasi kerja berpengaruh terhadap disiplin kerja karyawan bagian operasi PT Kereta Api Indonesia (Persero) Wilayah B Divisi Regional IV Tanjung Karang.

Hasil Uji $F$ digunakan untuk mengetahui apakah ada pengaruh yang signifikan antara variabel independen secara bersama-sama terhadap variabel depeden.
Hasil pengujian regresi secara bersama-sama bahwa $F_{\text {hitung }}$ sebesar 10,523 , sedangkan $F_{\text {tabel }}$ dengan df $1=2(k-1=3-1=2)$ dan df $2=92(n-k=$ 95-3=92) adalah sebesar 3,09 jadi $F_{\text {hitung }} 10,523$ $>F_{\text {tabel }}$ 3,09. Dengan demikian dapat disimpulkan bahwa pengawasan melekat dan motivasi kerja secara simultan berpengaruh terhadap disiplin kerja.

\section{SIMPULAN DAN SARAN}

\subsection{Simpulan}

Pengawasan melekat (waskat) dan motivasi kerja berpengaruh postitif terhadap disiplin kerja karyawan bagian operasi di PT. Kereta Api Indonesia (Persero) wilayah B Divisi Regional IV Tanjung Karang baik secara parsial maupun simultan. Koefisien determinasinya $\mathrm{R}^{2}$ ( $R$ Squares) sebesar 0,186 menunjukan bahwa disiplin kerja dipengaruhi pengawasan melekat dan motivasi kerja sebesar $18,6 \%$.

\subsection{Saran}

PT. Kereta Api Indonesia (Persero) Divisi Regional IV Tanjung Karang sebaiknya meningkatkan pengawasan terhadap karyawannya, khususnya karyawan bagian operasi wilayah $B$ dengan melakukan pengawasan melekat rutin dan terjadwal. Kemudian meningkatkan motivasi kerja karyawan dengan cara langsung (direct) yang bersifat khusus seperti pujian, penghargaan dan tunjangan agar kebutuhan serta kepuasan karyawan terpenuhi sehingga terbentuk karyawan yang loyal dan disiplin kerjanya tinggi.

\section{DAFTAR PUSTAKA}

Arikunto, Suharsimi. 2010. Prosedur Penelitian: Suatu Pendekatan Praktek. Jakarta: Rineka Cipta

Bangun, Wilson. 2012. Manajemen Sumber Daya Manusia. Jakarta: Erlangga

Baskoro, dkk. 2014. Pengaruh Motivasi Kerja dan Gaya Kepemimpinan Terhadap Disiplin Kerja Serta Dampaknya Pada Kinerja Karyawan (Studi Kasus Pada PT. PLN (Persero) APD Semarang). Jurnal Program Sudi Teknik Industri, Universitas Diponegoro 
Hafilah, Maxenta. 2013. Analisis Pengawasan Melekat Pimpinan Pada Pegawai Di Biro Umum Badan Nasional Penanggulangan Bencana. Skripsi Fakultas IImu Sosial Dan IImu Politik Universitas Indonesia

Hasibuan, Malayu, S. P. 2014. Manajemen Sumber Daya Manusia. Jakarta: Bumi Aksara

Mangkunegara, A. P. 2015. Manajemen Sumber Daya Manusia Perusahaan. Bandung: PT. Remaja Rosdakarya

Mardiono, Dian. 2014. Pengaruh Motivasi Dan Disiplin Kerja Terhadap Kepuasan Kerja Karyawan. Jurnal IImu \& Riset Manajemen STIESIA Surabaya

Martanto, Apri. 2016. Pengaruh Kepuasan, Motivasi Kerja Dan Komitmen Organisasional Terhadap Kinerja Karyawan. Jurnal Fakultas Ekonomi Universitas PGRI Yogyakarta

Nurrahman, Arif. 2014. Hubungan Pengawasan Melekat Dengan Disiplin Kerja Pegawai Di Badan Pemberdayaan Masyarakat
Dan Pemerintahan Desa Provinsi Kalimantan Timur. Jurnal Fakultas IImu Sosial Dan IImu Politik Universita Mulawarman

Oktaviana, Meliana. 2014. Hubungan Pengawasan Meleat Dengan Kinerja Pegawai Negeri Sipil Di Kantor Badan Kepegawaian Daerah Provinsi Kalimantan Timur. Jurnal Fakultas IImu Sosial Dan IImu Politik Universita Mulawarman

Sugiyono. 2017. Metode Penelitian Kuantutatif, Kualitatif dan R\&D. Bandung: Alfabeta

Sutrisno, Edy. 2016. Manajemen Sumber Daya Manusia. Cetakan ke-9. Jakarta: Kencana Prenadamedia Group

Utari, Khiki. 2015. Pengaruh Kepemimpinan dan Pengawasan Melekat Terhadap Disiplin Kerja Pegawai Di Dinas Pertambangan Dan Energi Kabupaten Kutai Timur. Jurnal Fakultas IImu Sosial Dan IImu Politik Universitas Mulawarman 